\title{
ZooDesign: Methods for Understanding and Facilitating Children's Education at Zoos
}

\author{
Ilyena Hirskyj-Douglas \\ Aalto University, Finland; University \\ of Glasgow, United Kingdom \\ ilyena.hirskyj- \\ douglas@glasgow.ac.uk
}

\author{
Stuart Gray \\ University of Bristol \\ United Kingdom \\ stuart.gray@bristol.ac.uk
}

\author{
Roosa Piitulainen \\ Aalto University \\ Helsinki, Finland \\ roosa.piitulainen@aalto.fi
}

\begin{abstract}
Zoos have been consistently popular with young visitors, helping educate children in animal conservation. However, zoos' typical strategies employ interactive signs and videos, which children largely ignore. In pursuit of new engagement methods, children were invited to design for animals via ZooDesign, a gamified imaginative design approach centred on an educational card and roleplaying game, ZooDesign assists children in envisaging how animals can use technologies, by exploring their welfare needs and humans' involvement. Many children designed with the animals' well-being in mind. Analysis of their creations and role-play interviews revealed that the method constitutes a good process but not all designs were appropriate for use with animals. Furthermore, few designs included the children themselves; most emphasised zookeeper and researcher roles instead. Building on child-computer interaction methods for zoo-based education contexts, the research raises key questions involved in educating children about animals.
\end{abstract}

\section{CCS CONCEPTS}

- Human-centered computing $\rightarrow$ Human computer interaction (HCI).

\section{KEYWORDS}

Child-Computer Interaction, Animal-Computer Interaction, Zoo, Education

\section{ACM Reference Format:}

Ilyena Hirskyj-Douglas, Stuart Gray, and Roosa Piitulainen. 2021. ZooDesign: Methods for Understanding and Facilitating Children's Education at Zoos. In Interaction Design and Children (IDC '21), fune 24-30, 2021, Athens, Greece. ACM, New York, NY, USA, 12 pages. https://doi.org/10.1145/3459990. 3460697

\section{INTRODUCTION}

Each year, more than 181 million people visit zoos or aquariums, with most of these visitors consisting of children and their caregivers [54]. One of the major motivations of people visiting a zoo, and for zoos themselves, is education [5]: 94\% of visitors feel that

Permission to make digital or hard copies of all or part of this work for personal or classroom use is granted without fee provided that copies are not made or distributed for profit or commercial advantage and that copies bear this notice and the full citation on the first page. Copyrights for components of this work owned by others than ACM must be honored. Abstracting with credit is permitted. To copy otherwise, or republish, to post on servers or to redistribute to lists, requires prior specific permission and/or a fee. Request permissions from permissions@acm.org.

IDC '21, fune 24-30, 2021, Athens, Greece

(C) 2021 Association for Computing Machinery.

ACM ISBN 978-1-4503-8452-0/21/06 ..\$15.00

https://doi.org/10.1145/3459990.3460697 zoos help teach children about how society can protect animals and the habitats that they depend upon [54]. This education process is nuanced, as it needs to be subtle and clever, especially for children. Typically, it is handled through presenting information and engaging experiences to children [55]. Recently technological devices have been introduced to educate children in zoos, including interactive sign- and tablet-based systems $[77,78]$ and augmentedreality mobile-phone systems [40]. While children are the visitors who most frequently use these systems, they often engage with these devices at only a surface level, without assimilating the digital content $[77,78]$. Thus, while technologies can enhance and provide a way to educate young people at zoos, in their current form they are not effective in reaching the design objective of facilitating deep visitor learning [62].

In consequence, zoos have changed how they employ technologies. Recently, animals have been given direct access to computerised systems [62, 77, 78]. These technologies, denoted in this paper as 'animal-involved technologies', are primarily for animals' own psychological and physiological well-being (sometimes referred to also as welfare enrichment), yet they have secondary education goals too $[29,77]$. For instance, some have speculated that seeing animals use computers enables people to see an animal's intelligence in action [62]. Moreover, letting visitors view animals using technologies has been shown to inspire interest and reinforce people's empathy for animals, creating an emotional connection and increasing inter-species understanding [29, 40, 77]. This, in turn, helps zoo visitors to learn about animals and the natural world and to internalise educational messaging [78]. With regard to children in particular, it has been posited that learning about animals also influences expressions of caring about the environment and conservation more generally [39]. There is a clear need for innovative education systems at zoos via which children can view animals' interaction alongside systems that they can also operate themselves.

In the field of child-computer interaction (CCI), a branch of research within $\mathrm{HCI}$ that emerged from exploring technology within education [64], there is a growing focus on children's involvement in the design of the systems they use. Still, for computer-enabled devices used in zoos, children are typically not involved in this process. Instead, it is commonplace for adults to be consulted exclusively - usually, the animals' keepers [30, 62], zoo education staff without technical expertise, and/or adult visitors [33, 77, 78]. While input from these adults is vital, in that they are experts in animal welfare, interaction design, and other fundamental aspects of zoo context, there is a noticeable lack of a child's perspective in designing educational experiences. Noting this, Pons et al. [62] examined 
children's involvement in the design of animal technologies, highlighting that design activities can help foster their critical thinking and relationships with animal species. Further, with children as co-designers of animal-involved technologies, there are opportunities to create better educational experiences and understand the roles that children see themselves, animals, technologies, and adults playing in design. Their involvement considers how children, as experts in their own zoo experiences, can be active in the design of the technologies they use.

This paper presents a participatory approach that addresses educational technologies' challenges in zoo settings via a series of connected activities we call ZooDesign. The ZooDesign experience resembles a workshop process that begins with a situated educational framing of zoo-housed animals and animal-involved technologies. A series of complementary imaginative design activities follows this, centred on an ideation-based card game. This game's rich design utilises animal and welfare-enrichment cards as entry points to requisite factors in animal-involved technologies, ideation sheets for design expression, and a role-play interview technique. In this game-style setting, children pick cards and sketch out their ideas, tell stories, role play, and model scenarios (involving interactions among animals, technologies, adults, and themselves). In this paper, we present the first test use of the ZooDesign concept, narrated through a workshop we ran with 12 child participants at Finland's Korkeasaari Zoo. The workshop resulted in 22 designideation presentations and narratives. Exploring the children's creations, we look at how our method facilitates children's learning about animals, on the basis of their drawings, creations, and interviews. The overarching insights produced help us speculate on how children see their and others' roles in zoo technologies. The project is articulated around the following research questions:

RQ1: How can we scaffold children's understandings of zoo animals via a participatory, imaginative design experience?

RQ2: How do children envisage the role of animal-involved technologies in zoo contexts?

\section{RELATED WORK}

\subsection{The Focus of Zoos' Education Efforts}

In a time of unprecedented devastation of the natural world and rapidly accelerating extinction of many species [61], zoos give children opportunities to learn about the protection of animals, their habitats, and adoption of sustainable behaviours [26]. Zoos help build children's knowledge and cognitive understanding of species, fostering human-animal empathy [48]. Thereby, they cultivate greater concern in children for animals through greater participation in conservation and tackling of environmental issues [24]. Nurturing a caring and compassionate attitude toward animals has been shown to support children's character development, particularly the blossoming of altruism-oriented traits [9, 47]. As Fraser has noted, opportunities to encounter zoo-housed animals engender visitors' exploration 'of their own environmental identities' and assist them to 'contemplate human responsibility to the biological world' [26].

Zoos commonly use written and graphical educational materials to support visitor learning via observation of animals. These materials describe conservation issues connected with the species exhibited, information about the individual animals in the enclosure (e.g., their history, relationships, and preferences), personalised information about animals' needs specific to a zoo setting and species' welfare needs $[25,26]$. These needs are often met through animalwelfare activities intended to stimulate species' natural behaviour and cognitive engagement, often by means of stimuli or granting animals greater choice and control in their environment $[51,80]$. This welfare enrichment occurs across five broadly defined key areas [51, 80]: 1) food enrichment (developing challenges related to ways of providing or manipulating food, such as hiding it or presenting it in new ways); 2) environmental enrichment (making changes to the physical space of the enclosure, such as introducing new natural or artificial structures via ground coverings); 3) sensory enrichment, via either natural or artificial sounds, smells, visual stimuli, or tactility (e.g., with animal noises/scents, mirrors, screens, and other materials); 4) social enrichment, encouraging or altering the dynamics of a group of animals (e.g., by introducing or removing animals); and 5) cognitive enrichment - a category that can encompass all other aspects of enrichment in bringing in encouragement of playful behaviour and cognitive challenges (through toys and other physical objects).

\subsection{Educational Technologies in Zoo-Based Learning}

Recognising the potential value of educational technologies for visitor learning [20,78], many modern zoos have implemented digitalised systems and created interactive signs and other resources to improve learning outcomes [16]. This mirrors the wider aims of supporting children's learning about nature and the outdoors through novel, often tangible technologies $[2,19]$. Through digital technologies, zoos build on visitors' observational experiences by providing interactions that share information about animals and encourage active exploration of their knowledge [16]. Nevertheless, much as with traditional signage [26], these digital technologies' effectiveness is questionable. Technologies are often not actively utilised by children, who struggle to assimilate educational information $[55,77,78]$. One reason is bound up with the separation between educational materials and the primary learning experience taking place in animal enclosures [40], a dichotomy reflected in adults' frequent direction of children's attention away from these interactive devices to view the animal directly [40, 78]. Moreover, children display a natural propensity for more socially constructed forms of learning and engagement within zoo contexts, drawing together observations of the animal with discussions that involve parents and other people [82]. Accordingly, various studies point to dialogue with zoo staff and better-integrated interactive experiences as preferable over solitary interactions with signage [44, 79].

In addition, today's use of either traditional signage or newer interactive derivatives in isolation may be plagued by a tendency to regard learning outcomes as directly proportional to visitor interactions with educational materials. Pedagogy theorists have long highlighted the differences between learning and education, however. Education is one approach to learning that traditionally encourages passive assimilation of content from teachers and artefact-based displays of knowledge $[1,57]$. This approach is sometimes criticised for limiting learning to short-term memorisation of knowledge 
that is quickly forgotten [63], often called 'surface learning' [46] In contrast, 'deep learning' is associated with longer-term retention of knowledge and an ability to use that knowledge in more complex ways - e.g., in extension of ideas, pattern recognition, putting knowledge to creative purposes or applying it in new settings, and critical reflection [46]. While learning may occur when educational materials are absorbed upon passive dissemination of knowledge, it becomes more deeply ingrained during a learner's use of that knowledge $[1,63]$. This is typically an involved and self-directed process of developing one's mental knowledge models, often through experimentation, first-hand experience, and social interactions with other learners $[1,63]$. Hence, some pedagogy theorists argue that education should exist to help frame and scaffold more participatory learning experiences.

Many zoos have begun to diversify visitor education beyond physical and digital signage; they are introducing programmes and experiences that foster other types of learning [23]. For instance, educational materials can be supported by in-person accompaniment of children's observations: zoos' education staff provide commentary on animal behaviours, verbally deliver educational content, engage in conversation, and answer questions [18]. Additionally, some zoos offer volunteer programmes that support participants' learning through training $[58,73]$. Accordingly, many zoos recognise the need for tighter integration of children's educational technologies with experiences of observing animals, to support visitor learning. Several zoos have recently collaborated with academics to develop novel animal-involved technologies that highlight animals' capabilities and elicit visitor empathy while, equally, addressing the animals' welfare requirements [29, 33, 77, 78]. These projects encourage visitors to experience animals' diverse behaviours [33] and simultaneously address cognitive and food-oriented welfare needs [29]. Meanwhile, others have deployed systems that allow children to interact with animals for purposes of facilitating direct learning and mutual engagement [62, 78]. Nevertheless, the design of such both educational and animal-involved technologies within zoos is fraught with tension and murkiness of children's role as key stakeholders. Since, as Hart [31] notes, 'it is important that all young people have the opportunity to learn to participate in programs which directly affect their lives', there is much work yet to be done to ascertain how children understand these technologies. Effectively supporting their learning and giving children more voice and a larger role within zoo technologies hinges on this. It is a sensitive matter, however: inviting children to design for animals can be deemed ethically challenging and to rest on precarious footing, as children may not understand animals' needs and requirements [62].

\subsection{Children's Role in Zoo-Based Educational Technologies}

Views on how best to empower and communicate with children in the design of educational technology in zoos are polarised. Within the CCI context, debate focuses on which roles are most appropriate for children in participatory processes [22, 66]. Under Druin's [22] design-partner model for child-centred design, children at their most involved are embraced in the role of 'design partner'. Here, they are fully integrated into adults' design teams and hold equal power over decisions, with immutable sway. Building on this theory, Read and colleagues [64, 65] further situate designing with children as a way of seeing and protecting children's dreams and ideals. These involvement processes can constitute valuable learning experiences that provide children with greater autonomy in their learning while embracing children's greater participation in technology design as citizens, in pursuit of improved engagement, effectiveness, and variety of children's learning experiences [6, 81].

At the other pole in models of involvement, children may participate in the design of technology as 'testers', providing feedback on the outputs of design decisions taken by adults [22, 38]. While this approach can yield valuable contributions, some would contend that failing to create conditions conducive to expanding children's agency risks their alienation [42]. Lack of deep involvement can produce inadequate systems, in which the technology is not fully representative of children's needs [42]. In the context of zoos and education, children thus far have been predominantly restricted to this limited realm - evaluating zoo exhibits and adult-scoped digital educational material $[55,78]$. In that role, children are often overlooked, with their contributions often parsed through the lens of parental opinions [26].

Noting this gap in children's involvement in animal technologies, Pons and Jaen [62] placed children in a co-designer's role by giving them cutouts of wild, pet, and zoo animals; humans; robots; tablets; robotics; computerised balls; and drones. Utilising these cutouts for a design task, they asked the children to create games for animals. Their report states that the children held anthropomorphic ideals for animals. Although these exhibited empathy, they also pointed to a need for a more nuanced method, one that supports children in developing more profound knowledge models related to animals and their requirements (such as welfare needs). This ties in with researchers' speculation that animals and children as computer users are similar in the challenges encountered in relation to participation and power within design processes [15, 34]. Scholars have suggested that these challenges for animal- and child-computer interaction could be addressed in conjunction. Thus situated, the understanding could support a shared knowledge space coalescing around theories and practices for these unique users. Participatory design approaches working with children in this manner may hold promise for more engaging zoo-based education technologies and examination of how power and participation are shared in multi-species contexts.

One crucial element for children's understanding of multi-species context and design-thinking abilities is empathy. Empathy forms a fundamental aspect of children's interpersonal development [17, 36]: children must cognitively assume other people's perspective (understand the world from another individual's point of view by placing themselves in their shoes) and assume the emotions of others (attempting to feel how others feel). As stated by Riess [68], 'compassion cannot exist without empathy, as they are part of the same perception and response continuum that moves human beings from observation to action'. Further, participatory approaches within CCI are imbued with the pedagogical ideals of 'constructivism', which stipulates that children actively construct mental knowledge models by building upon personal experiences of engaging with the world $[60,76]$. Here, knowledge is not passively absorbed. Rather, theories are constructed and challenged through experimentation 
and dialogue, creating connections between the new and previously established knowledge [59]. Although meaning-making is a personal endeavour, constructivism maintains that knowledge creation is a social and collaborative activity [75]. Interaction with collaborators lets learners check understanding, develop ideas, and synthesise others' knowledge into their own mental models [67] This vantage point renders constructivist approaches particularly well-aligned with socially constructed educational contexts of zoos that facilitate children's learning, refocusing, and interrogation of their understanding of zoos' animals [4].

Notwithstanding the potential here, decisions on the most appropriate role for children in the design of technology and about the education value of their participation often are subject to logistical challenges and project-specific constraints $[8,10]$. These issues are quite pronounced in the design of systems that involve children and animals as the main stakeholders [15, 62]. There is a need in these contexts for careful balance. This demands delving more deeply into how children can be further involved, served, and empowered in the zoo technologies from which they learn while the protection of all those involved is ensured.

\section{ZOODESIGN: A PLAYFUL DESIGN EXPERIENCE FOR CHILDREN}

\subsection{Motivations behind ZooDesign}

The discussion below describes our novel playful-design experience via a workshop which aimed to support children's learning about, and how they empathise with, zoo-housed animals and envisage animal-involved technologies. We created the participatory design experience for : 1) helping children build their knowledge of zoo species and empathy for them through the process of cognitive perspective-taking; 2) granting children opportunities to consolidate their understanding of zoo species and explore the topic of animal-involved technologies through constructionist ideation of knowledge from their own experiences of zoo exhibits and from educational materials; 3) scaffolding children's learning by means of autonomy and tailored educational content; 4) and using role play to encourage co-construction of knowledge about zoos among children, their peers, and adult experts.

The ZooDesign experience was developed to involve children of ages $8-12$, as children $<11$ years old constitute the majority $(57 \%)$ of visitors who frequent zoos [54]. Working with children this age, who have shorter attention spans than adults, presents unique challenges in terms of harnessing and sustaining engagement and motivation [37]. This factor was behind our choice of a creative and playful approach for ZooDesign, to encourage contextual exploration of ideas and artefacts from new perspectives with children $[13,65]$. The experience comprises a series of related activities providing children with educational material about the animals and technologies used at the zoo involved, alongside opportunities for more self-directed (though scaffolded) learning of these concepts. This took the form of a workshop featuring a guided zoo-exhibit tour, a talk on zoo-animal-involved technologies, explanation of the ideation-oriented card game, use of this game in zoo-technology prototyping, and role-playing interviews. The method's ideation cards were used with ideation sheets to structure the children's creative process and aid in their education. The ideation sheets are papers with space for drawings and modelling of artefacts that articulate participants' thoughts. Finally, the role-play interviews invited them to reflect upon their designs.

\subsection{Framing the Context of Zoo Animals and Their Enclosures: A Guided Exhibit Tour}

Getting children to imagine future scenarios with animals can be complex when their knowledge is not anchored in personal experience $[32,62]$. We proposed giving the children first-hand experience of observing animal-involved technologies to contextually situate their knowledge. Hence, the first activity in the ZooDesign workshop was a guided exhibit tour supported by zoo experts who, at each exhibit, described every animal's lived experience. They also identified any animal-involved technologies within the enclosure. After this brief educational framing, the children could ask questions and discuss the animals and any technologies present with the experts and with each other. We hoped that the tour's social nature would afford the children's development of a socially constructed understanding of animal-involved technologies through dialogue among themselves and with the expert staff and researchers.

\subsection{Educational Framing: A Talk about Zoo-Animal-Inclusive Technologies}

To help the children consolidate their sense of why welfare is a core requirement for animal-involved technologies, we held a short talk on the subject, delivered by one of the researchers following the tour. Helping children understand animal-involved technologies' welfare-enrichment requirements is particularly salient, as other stakeholders (i.e., zookeepers who make decisions aimed at the animals' best interests) deem them essential. We hoped that awareness of the multiple aspects of zoo-housed animals' welfare - food-related, environmental, sensory, social, and cognitive enrichment - would support the children's attempts to take animal perspectives (cognitive empathy) through greater understanding of animals' needs. The talk included videos and pictures of technologies used at Korkeasaari Zoo, at other zoos, and in research e.g. [27, 29, 77]. Korkeasaari Zoo's example was a wearable device for measuring tortoises' movement and surrounding temperature.

\subsection{Support for Perspective-taking and Engagement: An Ideation Card Game}

At the foundation of our method's imagination-rooted design activities are the ideation cards, consisting of decks of animal and welfare cards. Ideation cards are a commonly used tool in creative design games that resemble more traditional card games. When ideation cards are paired with simple game mechanics, the result can be considered a design game [12,35]; these mechanics may include turn-taking, revealing one's content, discarding cards that are no longer useful and adding further chance by drawing new ones, and nurturing collaborative design in a playful atmosphere [81]. Ideation cards also facilitate children's consolidation and communication of their thoughts via design thinking. From an education perspective, they can motivate children to put new knowledge to use, which may have powerful effects on the depth of learning. The ZooDesign experience's use of ideation cards to support 
children's exploration of zoo-housed animals' otherness builds on earlier work [62] in which children were given freedom to imagine any technologies and entities encompassed by the context, and it also draws on ideation methods developed for animal-enabled technologies $[32,43]$. Ideation cards allowed the creation of specific challenge scenarios as a focus for the design efforts, and they aided in elaborating on ideas, fostering conversation, and pacing the design activities [81]. This process creates several lenses for examining design challenges while creating a better understanding of the problem space in scaffolding children's learning (RQ1). For our ZooDesign game to foster their learning in zoo contexts, we needed to support the children via educational information about the specific animal for which they were designing. This support was given through animal cards, which covered eight animals: bears, camels, Barbary macaques, marmots, peacocks, sea eagles, tigers, and wild boars (see Fig. 1). Each animal card presents a picture of the animal; basic stats (height, weight, etc.); information about the animal's environment, nutrition needs, and social and play behaviours; and details on the individual housed at Korkeasaari Zoo. We chose these animals to include various taxa (birds, mammals, etc.) and species in close proximity to the zoo's workshop space. In the ideal case, we would have included aquatic and amphibian species, but Korkeasaari Zoo did not have these near the work area.

We also provided information on the animals' day-to-day welfareenrichment needs, through enrichment cards. Because the ZooDesign cards were aimed at children (ages 8-12) and enrichment for animals is a rather complex subject, we distilled various categories [71] down to five more child-friendly classes. The final set of ZooDesign enrichment cards comprised environment, food, sensory, social, and play cards (see Fig. 1).

\subsection{Developing and Communicating Mental Knowledge Models: Zoo-Technology Prototyping}

We used ideation sheets as a catalyst for paper-based and tangible low-fidelity creative-prototyping activities and to supply a medium for the children's physical construction and communication of their ideas beyond any limitations of the spoken word's description abilities [74]. These artefacts also served to reflect the extent of the participants' learning from the educational material delivered in the talk and zoo-exhibit tour. The ideation sheets had creation space and room for naming the creations, indicating which ZooDesign cards were used, and describing the designs (see the supplementary materials for the sheet). As for the ideation medium proper, developing prototypes with children is an exercise in 'learning-by-doing' - facilitating children's construction of mental knowledge models of the world around them [70]: in the ZooDesign context, knowledge models for the animals' world and animal-involved technologies.

We presented children with several ways to use the sheets. Sketching is one of the most prevalent techniques in work with children, empowering them to externalise internal thoughts and adding permanence to fleeting visions. Sketching is also a simple way of portraying visuospatial ideas directly, depicting the spatial relations between the various aspects of the design [11]. Hence, sketching affords rapid development of numerous complex ideas [72]. At the same time, it is crucial to be aware that children vary in how
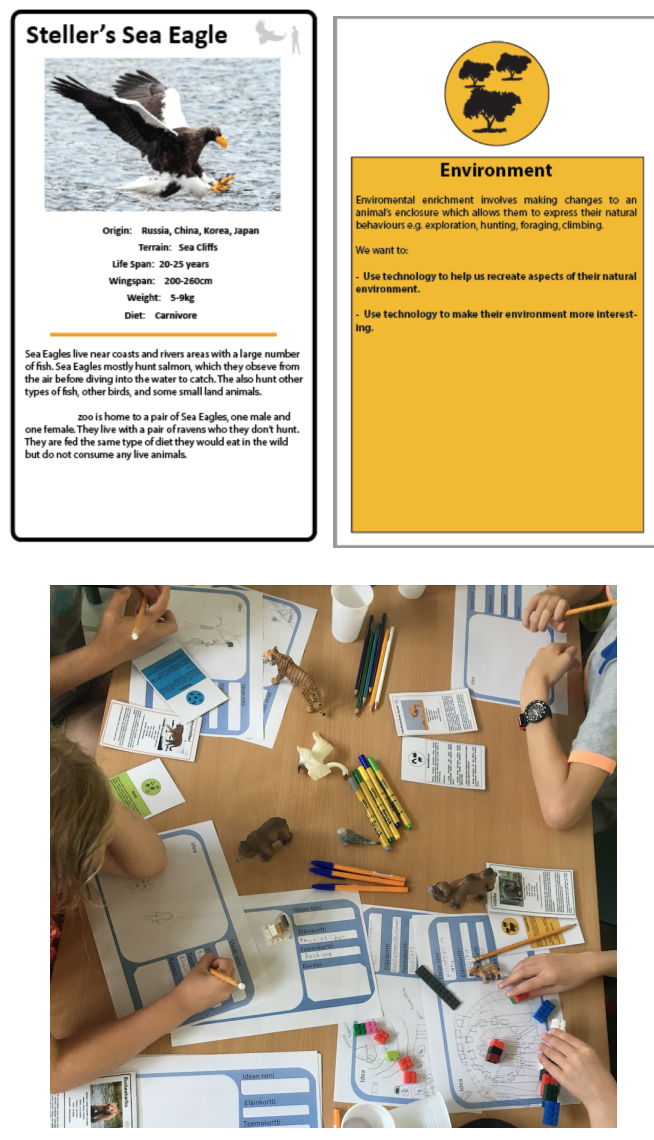

Figure 1: Left: A ZooDesign animal card (Sea Eagle) and enrichment card ('Environment'). The full set can be found in the supplementary materials. Right: Children ideating with cards, drawing sheets, pens, animal figures, LEGO, and colouring pencils.

they wish to express themselves in the context of prototyping [22]. Some children struggle with sketching as a self-expression method and are more motivated to construct their ideas physically [53]. Hence, we embraced Papert's paradigm of 'constructionism' [56] - a theory of education with constructivist foundations whereby children develop knowledge while engaged in the design of tangible or (more recently) digital objects, producing a rich internal mental model of knowledge. In implementing physical materials for construction with children, LEGO is one practical choice. It has cross-cultural application and a low skill threshold, afforded by its modularity/reconfigurability and its desirability within children's recreational play; therefore, it is a widely adopted design resource and aligned well with constructionist pedagogics $[28,50]$. For our workshop, we instructed participants to choose to draw, build, role play with the figures, or use any combination of these techniques on their ideation sheets. We provided colouring pencils, felt-tip markers, pens and pencils, LEGO bricks, and various animal figures. 


\subsection{Social and Playful Construction of Knowledge: Role-Play Interviews}

The core value of our process arises from overlaying discussion on the creations; as Mitchell reminds us [52], 'drawings are not a substitute for children's voices'. Asking children to talk about their work, where possible and of their own volition, empowers them to direct the path of their perceptions, with researchers placed in the position of listener [45]. Using role play to dramatise things and facilitate this discussion playfully can present individuals with an opportunity to reflect by conveying and further elaborating on the prototyped ideas and artefacts $[70,74]$. When establishing the scope of role playing in our design with children, we sought to give power to children's voices and remember that overly scripted and facilitator-led approaches risk drowning them out [3]. To support reflection and preserve the children's voices [70], the workshop employed a role-play method by letting them talk about their speculative designs via a news-story scenario. Our scenario involved a news reporter acting on behalf of a billionaire who was seeking scientists to create a futuristic zoo. This wealthy philanthropist had run out of ideas and wanted to hear from the children. For the role-playing scenario, one of the authors, wearing a press badge and suitable clothing, held a microphone for interviewing the children about their creations. The interview process was semi-structured but designed primarily to let the children talk to the 'reporter', and each other, about whatever they felt was important. The pseudoreporter approached only children who expressed a desire to talk about their design: the author was guided around the room by the children raising their hands and expressing an interest. If guidance was needed, the reporter would ask about the child's idea, referencing their designed artefact, and about the animal for whom they were designing for.

\section{THE WORKSHOP: AN OVERVIEW}

\subsection{Participants}

To obtain participants, Korkeasaari Zoo recruited 12 local children for the workshop, of ages 8-12 $(M=10)$, through an open call advertised via the zoo's mailing list of those having attended its summer-camp events. At these yearly camps, zookeepers and educators spend a week with children, teaching them about the zoo's animals, letting them participate in the enclosure- and habitat-cleaning activities, and building non-computerised enrichment devices for the animals. The 12 children taking part in the workshop were all those who responded to the zoo's invitation, some of whom knew each other from previous camps (though there were no siblings). To protect the children's identity we did not collect data on them, so we are limited in our association of ideas with specific participants.

\subsection{Procedure}

The invitation asked the children to take part in a workshop for designing 'technology elements, real or futuristic, that could be employed with animals within Korkeasaari Zoo in relation to their welfare and enrichment'. Three researchers hosted the workshop (two of whom were conducting research at the zoo), and a research co-ordinator at Korkeasaari Zoo assisted in the project. This fourth individual possesses expert knowledge of animals, their behaviour and physiology, and the zoo in question (from having worked there for several years). The workshop was two hours long and comprised the following phases: an introduction, the guided exhibit tour, the talk about zoo-animal-involved technologies, the ideation card game and prototyping, the role-play interviews, and closing activities.

We welcomed the children and introduced ourselves, then conducted the 30-minute tour of Korkeasaari Zoo. For the tour, we split the children into two groups, those aged 8-10 and 10-12, and tailored the content accordingly. The tour focused on the animals on the ZooDesign cards, visiting each and thus giving the children lived experience. In practice, the approach was child-led, with the children telling us (adults) about the animals, their summer-camp and other prior experience.

After the tour, there was time for refreshments before the 15minute talk about zoos' animal-involved technologies. When the talk was complete, we gave the children time to enquire about the animals and technologies. After this context and educational framing phase, we began the imaginative-design portion of the workshop, by introducing the ZooDesign task. We explained the rules of play and each of the cards before pausing for questions. The rules were simple: each child would begin by randomly picking a face-down card from the animal and the enrichment deck, then design a technology artefact on an ideation sheet with whatever medium seemed most comfortable. As facilitators and zoo staff, we were there to support the creation process by answering any questions that arose. This stage in the process was self-directed: the children could choose to work together, talk to each other, run around the room, or even ignore the game and play as they wished (indeed, during the workshop, one participant chose to build LEGO forts instead and make the animal figures fight, and another swapped the animal card drawn (a boar) for a bear, since bears were that child's favourite animal). This process of picking cards and creating speculative designs was conducted twice, in 20-minute iterations, so each child potentially had two designs.

After this process, the role-play method was applied for $15 \mathrm{~min}$ utes, with casual interviews of children who wanted to speak to our reporter character. One limitation we identified in the method was that not every child spoke about the designs - some chose not to. During this activity, children also excitedly created free-form new ideas for the billionaire about technologies for animals. However, these were often of an ad hoc nature and not conceptualised fully.

To close the workshop, we thanked the children for attending, and we invited their parents to see and hear more about their creations and discuss the workshop. Also, we gave the children certificates acknowledging their design participation. The children wanted to keep their creations after the workshop. Accordingly, via the zoo, we e-mailed the children copies of their sheets and photos of their creations.

\subsection{Analysis}

For our analysis, we gathered the children's 22 completed design sheets. In other preparatory work, two researchers who had been at the workshop and worked at the zoo played back the voice recordings of the role-play session. Quotations or mini transcripts were copied out on sticky notes, which were attached to the copy of 
the relevant child's drawing. Any observations not already documented that were captured in the notes taken at the time by the three researchers directly involved in the workshop were added to the details accompanying the drawing. If a child spoke about an undocumented concept during the ideation process, this formed a new a new cluster for the next phase.

The second phase of analysis proceeded thus: Two researchers, both of whom worked at the zoo, used inductive thematic analysis to label the ideation output with general codes and themes. Grouping was performed physically via the sticky notes and copies of the children's drawings generated in the process described above, with annotation, sorting, and adding of further information. We omitted the ad hoc suggestions created during the role-play session - it had become apparent that these usually lacked sufficient depth for analysis. Over several iterations, the process led to the following codes: technical/non-technical, active/passive user, animal monitoring, technology for learning about animals, games, robots, and inclusion of people. The codes for the noted themes are food, interaction mechanism, user focus, tangible, and social. Lastly, these codes were validated with the third researcher who had been present at the workshop, coding the data collected, before the team convened to discuss our process, codes, and themes. Via a series of analysisoriented discussion meetings, the three researchers developed a further code, age, reflecting the different ideation-styles among the children in consideration of the levels of prototype visible and how these were constructed.

\section{RESULTS}

Figure 2 covers the spectrum of the drawings created during the workshop, from the 22 designs.

\subsection{Foci: Technical/Non-Technical Systems and Monitoring}

Half of the drawings contained only non-technological artefacts, and the other half featured a computerised system of some sort. Often, the non-technological creations were modelled on puzzlelike toys inspired by the children's summer-camp experience of creating enrichment toys. Among the designs were a cuddly toy for tigers to play with (they are given balls at the zoo), a football for camels, bath interaction for peacocks, and a treat ball and mountainstream simulations for marmots (Fig. 2(d)). The technology-inspired designs focused on monitoring systems, such as one to monitor boars' digging activity (Fig. 2(c)), and technologies to help people learn about animals - for example, lick boards to discover animals' tastes (Fig. 2(j)).

\subsection{Humans' Inclusion and Roles, Active and Passive}

As for the actors in the children's vision of the future at the zoo, no creations but the camel drone (Fig. 2(g)) involved the children themselves or other children. For example, in the camel-drone drawing, the child explicitly mentioned not children but a more general 'human visitor'. The children did, however, envision adults in future technology systems. The lack of child roles stands in contrast against prior work, wherein children's creations often featured multiple child actors [62]. In another evident pattern, our participants placed adults in a passive role of monitoring or researching the animal rather than interacting directly. Their designs represent the human and animal components as having separate functions. As one child mentioned, 'one half of the thing could be inside the enclosure and one half outside where the keepers can go' (speaking about Fig. 2(i)). Children's first-hand observations of the passive technology within Korkeasaari Zoo could have shaped this role separation. There was a tendency for adults to be envisioned as receivers of information within concepts such as how rapidly a boar can dig and balance, what colours and tastes are more lickattractive to bears, how camels choose to use showers, and what music eagles might listen to.

\subsection{Games, Robotics, Tangibles, and Interaction Mechanisms}

Most ideation was game-focused; it featured elements of chasing (Fig. 2(g)), riding (Fig. 2(f)), playing with balls (the camel football), and balancing games (Fig. 2(j)). These designs also include advanced robotics, such as machines that make dead rabbits appear living (Fig. 2(b)) and doors that hide food so that tigers have to sniff out the meat (Fig. 2(a)). Most of the technologies envisioned use either tangibles or button interfaces (Fig. 2(c, h, i)). One child, the person behind Fig. 2(i), spoke thus about the buttons chosen: 'I was thinking about this thing for boars, since they like to press/push things.' In general, the interactions that the children envisioned for the animals varied from nose-, claw/foot-, and tongue-based to proximity-related interaction.

The children's ideation supported behaviour of three main sorts: 1) behaviour exhibited ordinarily in the zoo or the animals' natural environment (as with digging and listening to sea sounds; see Fig. 2(c, e)), 2) behaviour seen with domesticated animals outside a zoo context (e.g., licking as seen with lick mats for dogs; see Fig. $2(\mathrm{j})$ ), and 3 ) human-like actions (such as dancing or riding trains, as shown in Fig. 2(f)). Many of the designs (10/22) were intended to stimulate wild-type behaviour in zoo contexts (e.g., tigers chasing live prey and foraging/smelling to find food) or simulate a wild environment (with virtual streams, sea noises, rooms with different temperatures, etc.). The human-like behaviours (9/22) included camels playing football, tigers having cuddly toys, and camels playing with a drone.

\subsection{Food, Environmental, Cognitive, and Social Focus}

In most cases, design choices were specific to the category of enrichment envisioned. Food-related enrichment typically was handled in a non-technological manner - for instance, with puzzle-based feeders, use of smell, and chasing food. The food itself was used as a medium to provide opportunities for more wild and natural feeding behaviour. As one child mentioned, 'you see in nature they prey on actual living animals but in the zoo the animals they give them have to be dead' (a comment on Fig. 2(b)). Food was used also as a mediator, a reward for successful interaction, to assist the animal in understanding the system (e.g., a button-press interface) or entice the animal to start using it (as in the case of luring the boar into using the train cum Ferris wheel). This inclusion of food when children design for animals has been seen before [62] and may resonate 


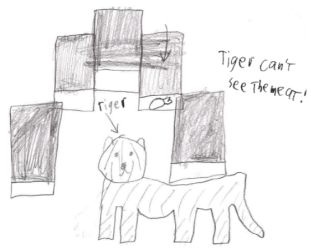

[a]

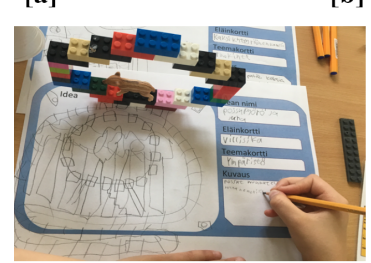

[f]

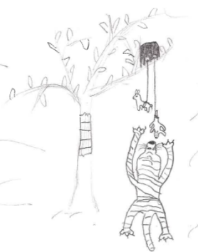

[b]

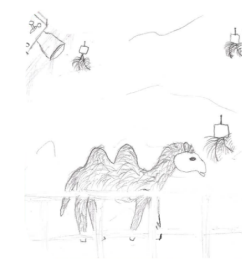

[g]

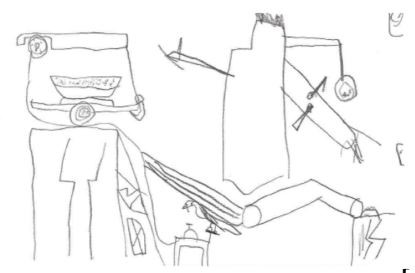

[c]

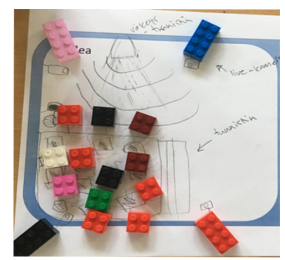

[h]

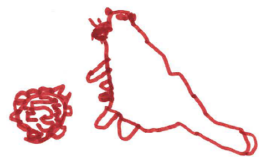

[d]

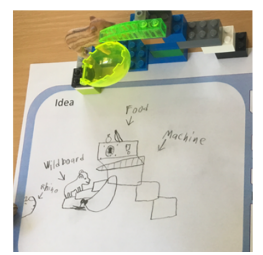

[i]

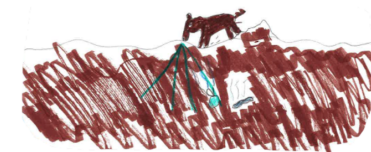

[e]

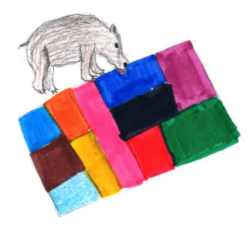

[j]

Figure 2: A selection from the range of children's drawings: [a] tigers find meat behind mechanical doors, [b] tigers hunt dead animals that are made to look alive, [c] a system where a sea eagle presses buttons to listen to music (including hanging toys and a temperature-controlled nest), [d] a marmot plays with a food-puzzle toy, [e] a sensor detects how rapidly boars are digging, [f] a boar travels around the zoo via a system with a Ferris wheel and train, [g] a camel chases a food-containing drone controlled by a human, [h] a device lets camels use buttons to control showers while humans watch via cameras, [i] a boar uses a balancing-stair device which dispenses food when a button is pressed, and [j] a bear reveals colour and taste preferences by licking the floor.

with children's more general experiences with animals. We suspect the emphasis on food in our context to be related to participants' prior creation of food-centric enrichment items for the animals, at the summer camp. This focus on food also is consistent with several animal-involved technology systems currently applying an incentive for food rewards at zoos [27, 29].

As for the environment category, children recognised that animals might want different objects in the enclosure. The range of designs included the streams for marmots, bathing water for peacocks, digging areas for boars, and temperature differences for tigers. With regard to sensory enrichment, the participants devised various mechanisms that might appeal to animals of particular species - from taste-based and visual to colour-oriented ones for bears, tactile ones (grabbing) for tigers, sounds and flashing colours for camels, and sounds (of the sea) for eagles. Proposals for cognitive enrichment entailed primarily puzzles that release food when the challenge is solved (as in Fig. 2(a, d, h, i)) or toys for animals (as with the cuddly toy and balls). Children working with the socialenrichment card did not present technological ideation: they produced such non-technological designs as the football to help camels play with each other. There were two exceptions; DropMachine allowed other boars present to eat the rewards and share the system's output, and Camel Energizer prompted animal-human interactions indirectly through the drone. With regard to social enrichment, participants asked the zoo's research co-ordinator whether some of the animals would even want to interact socially, given that some species typically live in solitude when in the wild (citing tigers as an example). The staff's response that contexts may differ between the wild and the zoo which may have led to some confusion around the appropriateness of social designs for zoo animals. This conversation demonstrates that the ZooDesign card game facilitates discussion surrounding animals' requirements, guiding children's focus with regard to a particular context. Both the food and the play category were highly prevalent and often interwoven with other categories. This suggests that children value these classes of enrichment especially which could be due to these classifications being self-evident for children. Playful behaviours may resonate particularly strongly with children, for whom play constitutes a source of opportunities for engagement and control [14]. The impetus behind the play within the children's conceptions was not so clear, and a bias toward human-type behaviour was visible. We suspect that the intentions behind their designing for play were benevolent ones of affording the animals opportunities similar to what they have as children. This anthropomorphic vantage point indicates that the ZooDesign method does not naturally focus all children's perspective on the animals' angle.

\section{DISCUSSION}

Reflecting on the use of ZooDesign to scaffold children's understanding of zoo animals, we ask, firstly, how children could be involved in future zoo education, both technology- and non-technologybased, and, secondly, what roles children may play in zoo technologies when both they themselves and non-human animals may be stakeholders.

\subsection{The ZooDesign Method for Scaffolding Children's Understanding of Zoo Animals}

Whatever role the children envisioned for themselves, the process of imagining futures for animals gave them an opportunity to experience a new education paradigm within a zoo context, with the goals of greater agency and encouraging deep learning. Our workshop embraced constructivist principles [60] by offering children an involvement-rich, social education experience grounded 
in their knowledge from the zoo's summer camp. Irrespective of the child's experience, the discourse-based tour with zoo experts and peers, followed by the talk on animal-involved technology, provided a basis for the children to garner deeper knowledge to synthesise with their animal observations. The main workshop activities tapped into constructionist [56] principles. The workshop allowed children to physically represent, experiment with, and refine their mental models of zoo-based animal-involved technology and their general understanding of individual animals in ways that are not commonly possible in most zoo visits. The LEGO pieces and toy animals were play-linked, reducing barriers to children's expression, thereby helping the researchers achieve richer interpretation of their ideas through embodied demonstration [66]. This multimodal method allowed the children to elaborate on the ideas they drew/wrote or re-conceptualise them physically after watching them play out. The method also helped other participants and the researchers alike immediately understand the design and, hence, engage the designer in discussion. Thereby, it contributed to co-creation of knowledge within the group, by affording checks of team members' understanding, clarification of elements of the design, suggestions, and co-operative brainstorming. For example, through discussing the DropMachine artefact with its child designer, we discovered that the system was designed for multiple boar users: the child considered that one boar might be better at climbing and fetch food for the rest. On the other hand, at times the LEGO and toys became a catalyst for over-excitement, such as play fighting and prototypes that were not relevant for the prescribed task. While these tools afford a self-directed approach and proved advantageous for creativity, the results do not always go in the direction that adults intend.

The engaging properties of the game and role play complemented the prototyping activities by capturing and holding the children's attention. As shown through the large proportion of ideation sheets completed (22/24), the card game's simple chance mechanics were enough to harness most of the children's attention and excitement potential for the prototyping and to guarantee understanding the rules. The process remained simple enough not to confuse the children or require further explanation beyond the category definitions. The imaginary roving reporter provided additional opportunities for social co-construction of knowledge. This role play gave children a platform to explain their ideas, listen to others, and negotiate the 'animal-involved technologies' concept with fellow participants - thus, the children could critically reflect on their designs. Beyond these contributions, the technique offered a rare opportunity for children to have a say, sharing their views of what their 'ideal' zoo exhibit should resemble and how they saw technologies, adults, animals, and themselves as part of the zoo. Our workshop clearly speaks to the value that role-playing opportunities can have within speculative and imaginative design with children, in line with the work of Pons and Jaen [62], to provide a guided process. While this facilitator-led approach runs a risk of becoming overbearing [3], our scenario ameliorated this by soliciting opinions and ideas from the children in the room and building on the idea of the children as 'the experts' while the adults present were there to learn from them. In this way, we reversed any perceived power imbalances caused by researcher facilitation of the activity. Consequently, while we believe that a series of workshops would be needed for greater complexity of children's mental models, development of workable educational-technology prototypes, and further exploration of the ZooDesign method, the process itself aligns with zoos' broader goals for education aimed at children's knowledge of and empathy for animals. On the basis of our results, we recommend that zoos employ our method for similar workshops with children to facilitate their understanding of zoo animals.

\subsection{Children's Roles in Zoos' Education Technologies}

Children should undoubtedly be involved in systems designed to educate them at zoos, as exemplified by the roles they envisioned for themselves. They viewed both themselves and the animals as stakeholders but as playing very different roles. In their creations, animals frequently were portrayed as what Lawson and colleagues [43] describe as usees [7] rather than users of technologies and items. For the children, things were done to the animals by computers without the animals' knowledge, whereas adults were observers or active users controlling the technology (i.e., its users). As childand animal-computer interaction research has noted [34, 49], this condition poses ethics problems, in that technologies should do things not to individuals but with them. Aspects of agency and ethics are complicated further in the zoo context. An individual such as a young child or an animal may not understand that the situation involves interacting with another being via technology or recognise what constitutes appropriate interaction for other users. This tension is evident in Camel Energizer: The camel may not find fun in the chase. Also, a child (or other user) may not play appropriately within the camels' parameters - e.g., moving too quickly or providing too little, or too much, food. Thus, there are clear ethics concerns 'on both sides of the fence' related to the roles children and animals play at zoos. Nevertheless, as Safina [69] notes, discovering similarities between ourselves and animals helps orient us to contemplating the world from animals' perspective, considering common roots and goals. These connections may be more pronounced for children, given the shared challenges related to self-determination. This worldview cements their capacity to advocate for the animal in many ways that adults cannot. Through children's various roles in the design process [49], their ambitions and requirements may dovetail with animals' such that the outcomes are in line with the interests of both. Education with this orientation may enable children to move beyond child-focused perspectives, to a joint, dual perspective as empathetic interpreters of animal-centred values.

Moreover, this dual perspective creates dialogue around what constitutes user-centred technologies within zoo contexts. The key stakeholders are animals (directly using the systems) and the children (being educated via that use). Said dual perspective is evident in the children's designs. Children in our study had different takes on the technologies when viewing them from the animals', researchers', visitors', and children's angle. Children saw researchers using technology to collect data and learn about animals, visitors using systems to engage with animals, and the animals being enriched by means of the technology in some form, while the children themselves were excluded. Most children were developmentally mature enough that they exhibited an ability to be emotionally empathic 
to the animals (i.e., demonstrating an intention to develop systems that enhance the animal's mood or respond to its welfare needs) and other stakeholders within the zoo context. The children faced a more significant challenge, however, in cognitively empathising with animals (i.e., designing systems congruent with an animal's cognitive and physical abilities). Therefore, investigating how children envision technologies to support animals and people could help to reveal ways of supporting children in various roles with the computer-enabled systems used at zoos. More studies and theory are needed to structure current discussion around multifaceted inter-species situations, such as those in zoo contexts.

At the same time, our ZooDesign experience demonstrates that, if children are going to be involved in creating technologies for education at zoos, the children must think beyond their own perspective so that the ensuing interactions are mutually beneficial and free of exploitation. Guided by our process, many children at the workshop did think in this manner, both considering natural behaviours seen within zoo contexts and aiming to pull wild natural behaviours into zoo environments. Although our process is an improvement on prior work [62], accounting for others' perspective constitutes a development-linked challenge and is something that improves with children's time and practice, as several authors have noted [21, 41]. Hence, while ZooDesign provides steps toward educating children about animals in zoo contexts, there are further steps, with more work yet to be done for helping children deeply learn and understand animals' needs and investigate their own role in the process.

\section{LIMITATIONS AND FURTHER WORK}

One constraint on this research is the locality and culture inherent to a case study in Finland. We plan to replicate this workshop in other settings and over a longer duration to build a more comprehensive picture of how children see animals, children's roles, the education process, and this method. Additionally, since the summercamp experience provided fairly advanced knowledge, further work is needed for making the method both exciting and accessible for a wider range of children. Unlike similar prior work [62], the children involved in this study were older and, hence, had a more developed view of the world, animals, and themselves (with more advanced cognitive abilities). That said, the method could be modified to suit different age groups. As for the process, while the role-playing activity initially intended for the children to sort their designs by value, we were sensitive to emotional challenges of peer review; for example, some might denigrate others' designs. The role play allowed a degree of informal evaluation; however, not all children wanted to be interviewed, so the method employed cannot sort children's ideation on its own. Future iterations should include additional child-led sorting methods. It would be beneficial if the structure of this part of the technique were oriented toward the questions the interviewer asked to uncover the role that education plays (e.g., 'what did you learn today?'). Lastly, although the activities described seem to resemble deep learning's (in involving knowledge elaboration, creativity, problem-solving, and critical reflection), we did not formally assess the children's learning. Comparing our approach to other educational experiences would require further work.

\section{CONCLUSION}

Our workshop-based study with 12 children responded to the need for new methods of educating children at zoos and for investigating what role children see themselves taking in future zoo technologies. The participatory and imaginative design approach utilised, ZooDesign, is aimed at facilitating and scaffolding children's learning and understanding about zoo animals' psychological and physiological needs. Analysing the outputs - from the 22 ideation artefacts produced via use of the enrichment and animal cards and, through role play, their further reflection upon their creations - helped us look at how children envisage and position technology at zoos to support animals, adults, and themselves. The children thought about technological and non-technological facets of zoo solutions that might stimulate animals' natural behaviour, replicate domestic animals' behaviour, or elicit human-style behaviour. Children envisioned diverse technologies for animals' use at zoos that could support multifaceted roles for participants such as researchers, adults, and zoo visitors but not for themselves. This tension highlights the core problem facing work on zoo-based educational technologies wherein computers have two purposes: to be used by animals and to educate children. ZooDesign process further facilitated children navigating concepts associated with agency, anthropomorphism, and appropriate interactions in zoo-based technology. Overall, ZooDesign appeared successful, in that most children envisioned systems that consider an animal's needs and requirements. However the method is neither perfect nor complete, but is a solid first step toward children actively developing technologies and leading their own education experiences in zoo contexts.

\section{SELECTION AND PARTICIPATION OF CHILDREN}

The zoo recruited children for the workshop via their existing education setting. Each child and parent/guardian was given information by the zoo prior to the workshop and agreed to take part in the study. The children and their parents were told that doing so was voluntary and that they could withdraw from participation in the workshop at any time. The zoo obtained written consent from each parent. We as researchers were not given access to any of their personal information. The participants did not receive any incentive to attend beyond free zoo admission for the child and parent. The workshop satisfied the ethics boards of Aalto University and Korkeasaari Zoo.

\section{ACKNOWLEDGMENTS}

We would like to thank Korkeasaari Zoo for hosting and supporting this workshop and all the children who took part.

\section{REFERENCES}

[1] Russell L. Ackoff and Daniel Greenberg. 2008. Turning Learning Right Side Up: Putting Education Back on Track. Pearson Prentice Hall.

[2] Ismo Alakärppä, Elisa Jaakkola, Jani Väyrynen, and Jonna Häkkilä. 2017. Using Nature Elements in Mobile AR for Education with Children. In Proceedings of the 19th International Conference on Human-Computer Interaction with Mobile Devices and Services (Vienna, Austria) (MobileHCI '17). Association for Computing Machinery, New York, NY, USA, Article 41, 13 pages. https://doi.org/10.1145/ 3098279.3098547

[3] Nadja Alexander and Michelle LeBaron. 2009. Death of the Role-Play. DRI Press. https://ink.library.smu.edu.sg/sol_research/1872/,booktitle= 
\{Rethinkingnegotiationteaching:Innovationsforcontextandculture\},numpages= $\{18\}$,

[4] Don Allison, Brian Wills, Doug Bowman, Jean Wineman, and Larry F. Hodges 1997. The Virtual Reality Gorilla Exhibit. IEEE Computer Graphics and Applications 17, 6 (1997), 30-38.

[5] Ursula S. Anderson, Angela S. Kelling, Robin Pressley-Keough, Mollie A. Bloomsmith, and Terry L. Maple. 2003. Enhancing the Zoo Visitor's Experience by Public Animal Training and Oral Interpretation at an Otter Exhibit. Environment and Behavior 35, 6, 826-841. https://doi.org/10.1177/0013916503254746

[6] A. Battou, O. Baz, and D. Mammass. 2018. An Interactive Adaptive Learning System Based on Agile Learner-Centered Design. EAI Endorsed Transactions on Smart Cities 3, 7 (Feb. 2018). https://doi.org/10.4108/eai.12-2-2018.154106

[7] Eric P.S. Baumer. 2015. Usees. In Proceedings of the 33rd Annual ACM Conference on Human Factors in Computing Systems (Seoul, Republic of Korea) (CHI '15). Association for Computing Machinery, New York, NY, USA, 3295-3298. https: //doi.org/10.1145/2702123.2702147

[8] Laura Benton, Hilary Johnson, Emma Ashwin, Mark Brosnan, and Beate Grawemeyer. 2012. Developing IDEAS: Supporting Children with Autism within a Participatory Design Team. In Proceedings of the SIGCHI Conference on Human Factors in Computing Systems (Austin, Texas, USA) (CHI '12). Association for Computing Machinery, New York, NY, USA, 2599-2608. https://doi.org/10.1145/ 2207676.2208650

[9] Sarah M. Bexell, Olga S. Jarrett, Luo Lan, Hu Yan, Estelle A. Sandhaus, Zhang Zhihe, and Terry L. Maple. 2007. Observing Panda Play: Implications for Zoo Programming and Conservation Efforts. Curator: The Museum fournal 50, 3 (2007), 287-297.

[10] Elizabeth Bonsignore, Derek Hansen, Anthony Pellicone, June Ahn, Kari Kraus, Steven Shumway, Kathryn Kaczmarek, Jeff Parkin, Jared Cardon, Jeff Sheets, Carlea Holl-Jensen, and Jes Koepfler. 2016. Traversing Transmedia Together: Co-Designing an Educational Alternate Reality Game for Teens, with Teens. In Proceedings of the 15th International Conference on Interaction Design and Children (Manchester, UK) (IDC '16). Association for Computing Machinery, New York, NY, USA, 11-24. https://doi.org/10.1145/2930674.2930712

[11] Matthias Book and André van der Hoek. 2018. Sketching with a Purpose: Moving from Supporting Modeling to Supporting Software Engineering Activities. In Proceedings of the 11th International Workshop on Cooperative and Human Aspects of Software Engineering (Gothenburg, Sweden) (CHASE '18). Association for Computing Machinery, New York, NY, USA, 93-96. https://doi.org/10.1145/ 3195836.3195854

[12] Eva Brandt and Camilla Grunnet. 2000. Evoking the Future: Drama and Props in User Centered Design.

[13] Eva Brandt and Jörn Messeter. 2004. Facilitating Collaboration through Design Games. In Proceedings of the Eighth Conference on Participatory Design: Artful Integration: Interweaving Media, Materials and Practices - Volume 1 (Toronto, Ontario, Canada) (PDC 04). Association for Computing Machinery, New York, NY, USA, 121-131. https://doi.org/10.1145/1011870.1011885

[14] Tina Bruce. 2019. Educating Young Children: A Lifetime fourney into a Froebelian Approach: The Selected Works of Tina Bruce. Routledge.

[15] Yoram Chisik and Clara Mancini. 2019. P for Politics D for Dialogue: Reflections on Participatory Design with Children and Animals. In Proceedings of the Sixth International Conference on Animal-Computer Interaction (Haifa, Israel) (ACI '19). Association for Computing Machinery, New York, NY, USA, Article 15, 13 pages. https://doi.org/10.1145/3371049.3371061

[16] Andrea W. Clay, Bonnie M. Perdue, Diann E. Gaalema, Francine L. Dolins, and Mollie A. Bloomsmith. 2011. The Use of Technology To Enhance Zoological Parks. Zoo Biology 30, 5 (2011), 487-497. https://doi.org/10.1002/zoo.20353 arXiv:https://onlinelibrary.wiley.com/doi/pdf/10.1002/zoo.20353

[17] Susan Clayton, John Fraser, and Claire Burgess. 2011. The Role of Zoos in Fostering Environmental Identity. Ecopsychology 3, 2 (2011), 87-96.

[18] Susan Clayton, John Fraser, and Carol D. Saunders. 2009. Zoo Experiences: Conversations, Connections, and Concern for Animals. Zoo Biology 28, 5 (2009) 377-397.

[19] Federica Delprino, Chiara Piva, Giovanni Tommasi, Mirko Gelsomini, Niccolò Izzo, and Maristella Matera. 2018. ABBOT: A Smart Toy Motivating Children To Become Outdoor Explorers. In Proceedings of the 2018 International Conference on Advanced Visual Interfaces (Castiglione della Pescaia, Grosseto, Italy) (AVI '18). Association for Computing Machinery, New York, NY, USA, Article 23, 9 pages. https://doi.org/10.1145/3206505.3206512

[20] Michele D. Dickey. 2005. Engaging by Design: How Engagement Strategies in Popular Computer and Video Games Can Inform Instructional Design. Educational Technology Research and Development 53, 2 (2005), 67-83.

[21] Eyal Doron. 2017. Fostering Creativity in School Aged Children through Perspective Taking and Visual Media Based Short Term Intervention Program. 23 (2017), 150-160), publisher = Elsevier Science, url = https://doi.org/10.1016/j.tsc.2016.12.003, doi $=10.1016 /$ j.tsc.2016.12.003, journal = Thinking Skills and Creativity,. Issue 3.

[22] Allison Druin. 2002. The Role of Children in the Design of New Technology. Behaviour \& Information Technology 21 (2002), 1-25.
[23] John H. Falk, Joseph Heimlich, and Kerry Bronnenkant. 2008. Using Identityrelated Visit Motivations As a Tool for Understanding adult Zoo and Aquarium Visitors' Meaning-making. Curator: The Museum fournal 51, 1 (2008), 55-79.

[24] John Howard Falk, Eric M. Reinhard, Cynthia Vernon, Kerry Bronnenkant, Heimlich Joe E., and Deans Nora L. 2007. Why Zoos \& Aquariums Matter: Assessing the Impact of a Visit to a Zoo or Aquarium. International fournal of Human-Computer Studies (2007), 24 pages. https://doi.org/10.1016/j.ijhcs.2016.05.003

[25] Eduardo J. Fernandez, Michael A. Tamborski, Sarah R. Pickens, and William Timberlake. 2009. Animal-Visitor Interactions in the Modern Zoo: Conflicts and Interventions. Applied Animal Behaviour Science 120, 1-2 (2009), 1-8.

[26] John Fraser. 2009. The Anticipated Utility of Zoos for Developing Moral Concern in Children. Curator: The Museum fournal 52, 4 (2009), 349-361. https://doi.org/10.1111/j.2151-6952.2009. tb00357.x arXiv:https://onlinelibrary.wiley.com/doi/pdf/10.1111/j.21516952.2009.tb00357.x

[27] Fiona French, Clara Mancini, and Helen Sharp. 2016. Exploring Methods for Interaction Design with Animals: A Case-Study with Valli. In Proceedings of the Third International Conference on Animal-Computer Interaction (Milton Keynes, UK) (ACI '16). Association for Computing Machinery, New York, NY, USA, Article 3, 5 pages. https://doi.org/10.1145/2995257.2995394

[28] Julia Anne Garde and Mashca C. van der Voort. 2017. Could LEGO® Serious Play ${ }^{\circledR}$ Be a Useful Technique for Product Co-Design? Proceedings of DRS 2016. Design + Research + Society Future-Focused Thinking (2017), 2045-2065.

[29] Stuart Gray, Fay Clark, Katy Burgess, Tom Metcalfe, Anja Kadijevic, Kirsten Cater, and Peter Bennett. 2018. Gorilla Game Lab: Exploring Modularity, Tangibility and Playful Engagement in Cognitive Enrichment Design. In Proceedings of the Fifth International Conference on Animal-Computer Interaction (Atlanta, Georgia, USA) (ACI '18). Association for Computing Machinery, New York, NY, USA, Article 6, 13 pages. https://doi.org/10.1145/3295598.3295604

[30] Stuart Iain Gray, Stephanie Campbell, Kirsten Cater, Chris Bevan, and Iain Gilchrist. 2018. Designing Games for Vision Screening: Lessons Learned from Observing Preschool Video Game Play. In Proceedings of the 2018 Annual Symposium on Computer-Human Interaction in Play Companion Extended Abstracts (Melbourne, VIC, Australia) (CHI PLAY'18 Extended Abstracts). Association for Computing Machinery, New York, NY, USA, 439-445. https://doi.org/10.1145/ 3270316.3271540

[31] Roger Hart, Collette Daiute, Selim Iltus, David Kritt, Michaela Rome, and Kim Sabo. 1997. Developmental Theory and Children's Participation in Community Organizations. Children and the Environment 24 (1997), 33-63. Issue 3. https: //www.jstor.org/stable/29767020

[32] Ilyena Hirskyj-Douglas and Andrés Lucero. 2019. On the Internet, Nobody Knows You're a Dog... Unless You're Another Dog. In Proceedings of the 2019 CHI Conference on Human Factors in Computing Systems (Glasgow, Scotland, UK) (CHI '19). Association for Computing Machinery, New York, NY, USA, 1-12. https://doi.org/10.1145/3290605.3300347

[33] Ilyena Hirskyj-Douglas and Roosa Piitulainen. 2020. Developing Zoo Technology Requirements for White-faced Saki Monkeys. International Conference on AnimalComputer Interaction (2020). https://doi.org/10.1145/3446002.3446123

[34] Ilyena Hirskyj-Douglas and Janet C. Read. 2014. Who Is Really in the Center of Dog Computer Design?. In Proceedings of the 2014 Workshops on Advances in Computer Entertainment Conference (Funchal, Portugal) (ACE '14 Workshops). Association for Computing Machinery, New York, NY, USA, Article 2, 5 pages. https://doi.org/10.1145/2693787.2693793

[35] Eva Hornecker. 2010. Creative Idea Exploration within the Structure of a Guiding Framework: The Card Brainstorming Game. In Proceedings of the Fourth International Conference on Tangible, Embedded, and Embodied Interaction (Cambridge, Massachusetts, USA) (TEI '10). Association for Computing Machinery, New York, NY, USA, 101-108. https://doi.org/10.1145/1709886.1709905

[36] Tiffani J. Howell, Emily M. McLeod, and Grahame J. Coleman. 2019. When Zoo Visitors 'Connect' with a Zoo Animal, What Does That Mean? Zoo Biology 38, 6 (2019), 461-470.

[37] Wendy Hsin-Yuan Huang and Dilip Soman. 2013. A Practitioner's Guide to Gamification of Education. Retrieved June 24, 2020 from https://inside.rotman.utoronto.ca/behaviouraleconomicsinaction/files/2013/ 09/GuideGamificationEducationDec2013.pdf

[38] Ole Sejer Iversen, Rachel Charlotte Smith, and Christian Dindler. 2017. Child As Protagonist: Expanding the Role of Children in Participatory Design. In Proceedings of the 2017 Conference on Interaction Design and Children (Stanford, California, USA) (IDC '17). Association for Computing Machinery, New York, NY, USA, 27-37. https://doi.org/10.1145/3078072.3079725

[39] Olin E. Myers Jr, Carol D. Saunders, and Erik Garrett. 2004. What Do Children Think Animals Need? Developmental Trends. Environmental Education Research 10, 4 (2004), 545-562. https://doi.org/10.1080/1350462042000291056

[40] Nicholas Kelling and Angela Kelling. 2014. Zooar: Zoo Based Augmented Reality Signage. In Proceedings of the Human Factors and Ergonomics Society Annual Meeting, Vol. 58. SAGE Publications (Los Angeles, CA, USA), 1099-1103.

[41] Ha Yeon Kim, Maria D. LaRusso, Lisa B. Hsin, Allen G. Harbaugh, Robert L. Selman, and Catherine E. Snow. 2018. Social Perspective-taking Performance: 
Construct, Measurement, and Relations with Academic Performance and Engagement. Fournal of Applied Developmental Psychology 57 (2018), 24-41. https://doi.org/10.1016/j.appdev.2018.05.005

[42] Marianne Kinnula and Netta Iivari. 2019. Empowered To Make a Change: Guidelines for Empowering the Young Generation in and through Digital Technology Design. In Proceedings of the FabLearn Europe 2019 Conference (Oulu, Finland) (FabLearn Europe '19). Association for Computing Machinery, New York, NY, USA, Article 16, 8 pages. https://doi.org/10.1145/3335055.3335071

[43] Shaun Lawson, Ben Kirman, and Conor Linehan. 2016. Power, Participation, and the Dog Internet. Interactions 23, 4 (June 2016), 37-41. https://doi.org/10.1145/ 2942442

[44] Petra Lindemann-Matthies and Tobias Kamer. 2006. The Influence of an Interactive Educational Approach on Visitors' Learning in a Swiss Zoo. Science Education 90, 2 (2006), 296-315.

[45] Ioana Literat. 2013. 'A Pencil for Your Thoughts': Participatory Drawing As a Visual Research Method with Children and Youth. International fournal of Qualitative Methods 12 (2013). Issue 1. https://doi.org/10.1177/160940691301200143

[46] P. Lombardi. 2019. Instructional Methods, Strategies and Technologies To Meet the Needs of All Learners.

[47] Konrad Lorenz. 2013. The Foundations of Ethology. Springer Science \& Business Media.

[48] Jerry F. Luebke and Jennifer Matiasek. 2013. An Exploratory Study of Zoo Visitors' Exhibit Experiences and Reactions. Zoo Biology 32, 4 (2013), 407-416.

[49] Panos Markopoulos and Mathilde Bekker. 2003. Interaction Design and Children Interacting with Computers 15 (2003), 141-149. https://doi.org/10.1016/S09535438(03)00004-3

[50] David Mathias, Chris Snider, Ben Hicks, and Charlie Ranscombe. 2019. Acceler ating Product Prototyping through Hybrid Methods: Coupling 3D Printing and LEGO. Design Studies 62 (2019), 68-99. https://doi.org/10.1016/j.destud.2019.04. 003

[51] David J. Mellor, Susan Hunt, and Markus Gusset. 2015. Caring for Wildlife: The World Zoo and Aquarium Animal Welfare Strategy. WAZA Executive Office (2015).

[52] Lisa M. Mitchell. 2008. Child-centered? Thinking Critically about Children's Drawings As a Visual Research Method. Visual Anthropology Review 22 (2008) Issue 1. https://doi.org/10.1525/var.2006.22.1.60

[53] Obaid Mohammad, Gökçe Baykal, Asim Evren Yantaç, and Wolmet Barendregt 2018. Developing a Prototyping Method for Involving Children in the Design of Classroom Robots. Interational fournal of Social Robotics 10 (2018), 279-291. https://doi.org/10.1007/s12369-017-0450-7

[54] Association of Zoos and Aquariums (AZA). 2020. . Retrieved 29 June 2020 from https://www.aza.org/partnerships-visitor-demographics

[55] Yutaro Ohashi, Hideaki Ogawa, and Makoto Arisawa. 2008. Making New Learning Environment in Zoo by Adopting Mobile Devices. In Proceedings of the 10th International Conference on Human-Computer Interaction with Mobile Devices and Services (Amsterdam, Netherlands) (MobileHCI '08). Association for Computing Machinery, New York, NY, USA, 489-490. https://doi.org/10.1145/1409240.1409323

[56] Seymour Papert. 1990. Children, Computers and Powerful Ideas. Basic Books.

[57] Patricia G. Patrick. 2016. Graduate Students Define and Redefine Informal Science Education. In Electronic Proceedings of the ESERA 2015 Conference - Science Education Research: Engaging Learners for a Sustainable Future, Vol. 9. 1270-1279.

[58] Patricia G. Patrick, Catherine E. Matthews, David Franklin Ayers, and Sue Dale Tunnicliffe. 2007. Conservation and Education: Prominent Themes in Zoo Mission Statements. The fournal of Environmental Education 38, 3 (2007), 53-60.

[59] Denis C. Phillips. 1995. The Good, the Bad, and the Ugly: The Many Faces of Constructivism. Educational Researcher 24, 7 (1995), 5-12.

[60] J. Piaget and B. Inhelder. 1967. Systems of Reference and Horizontal-Vertical Coordinates. The Child's Conception of Space (1967), 375-418.

[61] Brad Plumer. 2019. Humans Are Speeding Extinction and Altering the Natural World at an 'Unprecedented' Pace. The New York Times (2019).

[62] Patricia Pons and Javier Jaen. 2017. Designing Interspecies Playful Interactions: Studying Children Perceptions of Games with Animals. In Proceedings of the Fourth International Conference on Animal-Computer Interaction (Milton Keynes, UK) (ACI2017). Association for Computing Machinery, New York, NY, USA Article 12, 12 pages. https://doi.org/10.1145/3152130.3152139
[63] Detlef R. Prozesky. 2000. Teaching and Learning. Community Eye Health 13, 36 (2000), 60-61.

[64] Janet Read. 2015. Children As Participants in Design and Evaluation. Interactions 22, 2 (Feb. 2015), 64-66. https://doi.org/10.1145/2735710

[65] Janet C. Read. 2008. Validating the Fun Toolkit: An Instrument for Measuring Children's Opinions of Technology. Cognition, Technology, \& Work 10, 2 (March 2008), 119-128. https://doi.org/10.1007/s10111-007-0069-9

[66] Janet C. Read, Daniel Fitton, and Matthew Horton. 2014. Giving Ideas an Equal Chance: Inclusion and Representation in Participatory Design with Children. In Proceedings of the 2014 Conference on Interaction Design and Children (Aarhus, Denmark) (IDC '14). Association for Computing Machinery, New York, NY, USA, 105-114. https://doi.org/10.1145/2593968.2593986

[67] Alina Reznitskaya, Richard C. Anderson, and Li-Jen Kuo. 2007. Teaching and Learning Argumentation. The Elementary School fournal 107, 5 (2007), 449-472.

[68] Helen Riess. 2017. The Science of Empathy. Fournal of Patient Experience 4, 2 (2017), 74-77.

[69] Carl Safina. 2015. Beyond Words: What Animals Think and Feel. Macmillan.

[70] Selina Schepers, Katrien Dreessen, and Bieke Zaman. 2018. Exploring User Gains in Participatory Design Processes with Vulnerable Children. In Proceedings of the 15th Participatory Design Conference: Short Papers, Situated Actions, Workshops and Tutorial - Volume 2 (Hasselt and Genk, Belgium) (PDC '18). Association for Computing Machinery, New York, NY, USA, Article 25, 5 pages. https: //doi.org/10.1145/3210604.3210617

[71] Cristiano Schetini de Azevedo, Cynthia Fernandes Cipreste, and Robert John Younge. 2006. Environmental Enrichment: A GAP Analysis. 102 (2006), 329-343. Issue 3-4. https://doi.org/10.1016/j.applanim.2006.05.034

[72] Reinhard Sefelin, Manfred Tscheligi, and Verena Giller. 2003. Paper Prototyping What Is It Good For? A Comparison of Paper- and Computer-based Low-Fidelity Prototyping. In CHI '03 Extended Abstracts on Human Factors in Computing Systems (Fort Lauderdale, Florida, USA) (CHI EA '03). Association for Computing Machinery, New York, NY, USA, 778-779. https://doi.org/10.1145/765891.765986

[73] Brigitte Seybold, Thomas Braunbeck, and Christoph Randler. 2014. Primate Conservation - an Evaluation of Two Different Educational Programs in Germany. International fournal of Science and Mathematics Education 12, 2 (2014), 285-305.

[74] Dag Svanaes and Gry Seland. 2004. Putting the Users Center Stage: Role Playing and Low-Fi Prototyping Enable End Users To Design Mobile Systems. In Proceedings of the SIGCHI Conference on Human Factors in Computing Systems (Vienna, Austria) (CHI '04). Association for Computing Machinery, New York, NY, USA, 479-486. https://doi.org/10.1145/985692.985753

[75] Lev Vygotsky. 1978. Interaction between Learning and Development. Readings on the Development of Children 23, 3 (1978), 34-41.

[76] Lev Semenovich Vygotsky. 1980. Mind in Society: The Development of Higher Psychological Processes. Harvard University Press.

[77] Sarah Webber, Marcus Carter, Sally Sherwen, Wally Smith, Zaher Joukhadar, and Frank Vetere. 2017. Kinecting with Orangutans: Zoo Visitors' Empathetic Responses to Animals' Use of Interactive Technology. In Proceedings of the 2017 CHI Conference on Human Factors in Computing Systems (Denver, Colorado, USA) (CHI '17). Association for Computing Machinery, New York, NY, USA, 6075-6088. https://doi.org/10.1145/3025453.3025729

[78] Sarah Webber, Marcus Carter, Wally Smith, and Frank Vetere. 2017. Interactive Technology and Human-Animal Encounters at the Zoo. International fournal of Human-Computer Studies 98, C (Feb. 2017), 150-168. https://doi.org/10.1016/j. ijhcs.2016.05.003

[79] Robert L. Wolf and Barbara L. Tymitz. 1979. 'Do Giraffes Ever Sit?': A Study of Visitor Perceptions at the National Zoological Park, Smithsonian Institution. ERIC.

[80] Sarah Wolfensohn. 2015. Applied Animal Welfare. The Veterinary Record 177, 23 (2015), 600.

[81] Peta Wyeth, Carla Diercke, and Stephen Viller. 2006. Design for Inspiration: Children, Personal Connections and Educational Technology. In Proceedings of the 18th Australia Conference on Computer-Human Interaction: Design: Activities, Artefacts and Environments (Sydney, Australia) (OZCHI '06). Association for Computing Machinery, New York, NY, USA, 365-368. https://doi.org/10.1145/ 1228175.1228247

[82] Katheryn Zelak et al. 2018. An Exploratory Study of Factors Influencing Zoo Educator Message Communication. Ph.D. Dissertation. The Ohio State University. 